\title{
Iberian-Balearic fern regions and their explanatory variables
}

\author{
Juan Carlos Moreno Saiz · Jorge M. Lobo
}

Published online: 31 January 2008

(C) Springer Science+Business Media B.V. 2008

\section{Erratum to: Plant Ecol \\ DOI 10.1007/s11258-007-9392-8}

This erratum corrects Figure 8 and its legend accordingly.

Figure 8 along with its legends were incorrectly published with errors in the original publication.

J. C. Moreno Saiz $(\bowtie)$

Departamento de Biología (Botánica), Universidad Autónoma de Madrid, c/Darwin 2, 28049 Madrid, Spain e-mail: jcarlos.moreno@uam.es

J. M. Lobo

Departamento de Biodiversidad y Biología Evolutiva, Museo Nacional de Ciencias Naturales, C.S.I.C., Madrid, Spain 


\begin{tabular}{|c|c|c|c|c|c|c|c|c|c|c|c|c|c|c|c|c|c|c|c|c|c|c|}
\hline & & 35 & 26 & 38 & 45 & 49 & 36 & 31 & 25 & 25 & 33 & & & & & & & & & & & \\
\hline 21 & 13 & 26 & 31 & 29 & 49 & 54 & 54 & 52 & 47 & 43 & 50 & 53 & 55 & & & & & & & & & \\
\hline \multirow[t]{7}{*}{28} & 34 & 14 & 33 & 32 & 24 & 29 & 22 & 22 & 19 & 29 & 33 & 35 & 34 & 46 & 53 & 54 & 59 & & & & & \\
\hline & 35 & 34 & 34 & 36 & 22 & 20 & 10 & 10 & 5 & 30 & 33 & 26 & 20 & 23 & 20 & 27 & 35 & 42 & 53 & 48 & 32 & \\
\hline & 43 & 34 & 25 & 28 & 24 & 17 & 13 & 7 & 6 & 14 & 22 & 20 & 20 & 12 & 8 & 11 & 13 & 19 & 35 & 40 & 22 & \\
\hline & 39 & 37 & 31 & 35 & 32 & 27 & 13 & 12 & 22 & 27 & 12 & 16 & 21 & 8 & 6 & 15 & 24 & 12 & 25 & & & \\
\hline & 27 & 20 & 29 & 37 & 27 & 19 & 14 & 14 & 31 & 20 & 12 & 29 & 30 & 13 & 17 & 29 & 10 & & & & & \\
\hline & 27 & 30 & 21 & 31 & 35 & 38 & 27 & 33 & 32 & 19 & 18 & 18 & 24 & 18 & 23 & 19 & & & & & & \\
\hline & 19 & 20 & 23 & 18 & 28 & 34 & 16 & 18 & 22 & 14 & 8 & 9 & 19 & 18 & 18 & & & & & & & 25 \\
\hline 16 & 28 & 21 & 25 & 22 & 12 & 44 & 23 & 15 & 11 & 14 & 9 & 10 & 11 & 12 & 14 & & & & & 26 & 14 & \\
\hline 27 & 24 & 15 & 21 & 21 & 23 & 22 & 15 & 9 & 21 & 13 & 8 & 5 & 9 & 15 & 15 & & & 7 & & & & \\
\hline \multirow[t]{6}{*}{27} & 23 & 15 & 27 & 16 & 10 & 13 & 16 & 12 & 15 & 14 & 19 & 10 & 8 & 16 & 17 & 24 & & 19 & & & & \\
\hline & 13 & 13 & 16 & 15 & 23 & 16 & 16 & 19 & 18 & 23 & 34 & 18 & 18 & 17 & & & & & & & & \\
\hline & 19 & 20 & 15 & 19 & 23 & 22 & 15 & 10 & 26 & 25 & 30 & 17 & 11 & 12 & & & & & & & & \\
\hline & 20 & 15 & 14 & 13 & 20 & 27 & 13 & 20 & 12 & 39 & 25 & 17 & 7 & & & & & & & & & \\
\hline & & & & & 20 & 38 & 26 & 20 & 22 & 34 & 32 & 23 & & & & & & & & & & \\
\hline & & & & & 14 & 32 & 26 & & & & & & & & & & & & & & & \\
\hline
\end{tabular}

Fig. 8 Number of pteridophyte species in the 257 considered $50 \times 50 \mathrm{~km}$ Iberian UTM cells. Tones of grey represent the four species richness quartiles 